\title{
Magnetic Resonance Imaging-Measured Adductor Muscle Volume and 100 m Sprint Running Performance in Female Sprinters
}

\author{
Tomohiro Yasuda ${ }^{1}$, Kazuhisa Kawamoto² ${ }^{2}$ Jeremy P. Loenneke ${ }^{3}$, Takashi Abe ${ }^{3 *}$ \\ ${ }^{1}$ School of Nursing, Seirei Christopher University, Shizuoka, Japan \\ ${ }^{2}$ Faculty of Human Development and Culture, Fukushima University, Fukushima, Japan \\ ${ }^{3}$ Department of Health, Exercise Science and Recreational Management, Kevser Ermin Applied Physiology Laboratory, The \\ University of Mississippi, University, MS, USA \\ Email: t12abe@gmail.com
}

How to cite this paper: Yasuda, T., Kawamoto, K., Loenneke, J.P. and Abe, T. (2019) Magnetic Resonance ImagingMeasured Adductor Muscle Volume and 100 m Sprint Running Performance in Female Sprinters. International Journal of Clinical Medicine, 10, 469-476.

https://doi.org/10.4236/ijcm.2019.1010040

Received: September 18, 2019

Accepted: October 11, 2019

Published: October 14, 2019

Copyright $\odot 2019$ by author(s) and Scientific Research Publishing Inc. This work is licensed under the Creative Commons Attribution International License (CC BY 4.0).

http://creativecommons.org/licenses/by/4.0/

\begin{abstract}
The purpose of this study was to determine the specific muscles that may contribute to sprint performance. Eleven female $100-\mathrm{m}$ sprinters and nine non-sprinters volunteered. Thigh muscle volume (MV) was measured using magnetic resonance imaging (MRI) images obtained from the spina iliaca anterior-superior to below the distal end of the femur. The MV of the adductors, quadriceps and hamstrings was calculated. Evidence for the null/alternative hypothesis was provided thorough the calculation of Bayes Factors $\left(\mathrm{BF}_{10}\right)$. Differences represented as median $\delta(95 \%$ credible interval). Absolute MVs in the quadriceps [1.287 (0.315, 2.39), $\mathrm{BF}_{10}: 14.3$ ], hamstrings [3.032 (1.886, 4.482), $\mathrm{BF}_{10}$ : 9487.4] and adductors [3.22 (1.994, 4.654), $\left.\mathrm{BF}_{10}: 23,360.2\right]$ were greater in sprinters than in non-sprinters. This was also observed when MV was normalized to body mass $\left(\mathrm{cm}^{3} / \mathrm{kg}\right)$. Absolute and relative MVs in the adductor longus, the adductor brevis, the adductor magnus, pectineus, and gracilis were also greater in the sprinters. However, percentage of component adductor relative to total adductors MV appeared similar between the two groups. There was no evidence for a correlation between sprint time and quadriceps, hamstrings and adductors MV relative to body mass. Within the adductors, there was evidence for a correlation between sprint time and adductor brevis MV relative to body mass $\left[\mathrm{r}=-0.652, \mathrm{BF}_{10}: 3.028, \delta-0.548(-0.870,0.040)\right]$. Although the credible interval was wide, our results suggest that the adductor brevis may contribute to sprint running performance in female sprinters. This may be related, in part, to supporting the flexion and medial rotation of the thigh.
\end{abstract}




\section{Keywords}

Body Composition, Female Athletes, Magnetic Resonance Imaging, Muscle Mass, 100-m Dash

\section{Introduction}

Magnetic resonance imaging (MRI) of the lower extremities and trunk muscles in sprinters has been studied by several researchers [1] [2] [3] [4] in an effort to examine the specific muscles that contribute to sprint running performance (i.e. best 30 - $100 \mathrm{~m}$ dash time or maximal running speed). For instance, Hoshikawa et al. [2] reported that a larger muscle cross-sectional area (CSA) of the psoas major relative to quadriceps muscle CSA was correlated with a season-best 100 $\mathrm{m}$ time in 22 junior male and 22 junior female sprinters. Similarly, Copaver et al. [1] observed a correlation between sprint performance $(50 \mathrm{~m}$ and $120 \mathrm{~m}$ dash times) and psoas major muscle CSA as well as hip flexion power in 10 Afro Caribbean athletes including soccer, tennis, track and field, and combat sports. Recently, a study by Sugisaki et al. [4] reported correlations between the season best $100 \mathrm{~m}$ time and absolute muscle volume of the psoas major, gluteus maximus, gluteus medius plus minimus, and hamstrings, while other muscles include adductors which did not correlate to the performance in 31 Japanese male sprinters. These findings suggest that the psoas major and gluteus maximus, which act as flexion or extension of the thigh, may be specific muscles that contribute to sprint running performance.

The adductors consist of three major muscles namely the adductor longus, adductor brevis, and adductor magnus with the primary function known as a hip adduction and a medially/laterally rotation of the thigh [5]. During sprint running, however, these muscles perform different functions at different moments of the action. For example, the adductor longus located in anteromedial thigh acts to flex the hip just after toe-off and remains active during the follow-through and early forward swing [6], while the adductor magnus located in posteromedial thigh acts to extend the hip from the flexed position during backward swing [7]. From the studies of electromyography [6] [7], the functions of the adductors may be not only hip adduction and lateral rotation of the thigh but also contributes to hip extension and flexion during sprint running. However, it is unknown how each individual adductor correlates with sprint performance in sprinters. Thus, the purpose of this study was to determine how muscle volume differed between sprinters and non-sprinters and determine the relationship between individual adductor muscles and sprint performance. If a correlation does exist, this might suggest an important role of that particular muscle during sprinting and may offer a target of emphasis for future researchers and practitioners. 


\section{Methods}

Eleven female competitive 100-m sprinters (competing at least at national level) and nine age-matched college students (non-sprinters) were recruited for the study. The body composition of the sprinters and non-sprinters are indicated in Table 1. The best official time $(100 \mathrm{~m})$ was used for evaluating sprint performance. The sprinters contain five elite sprinters who participated in the World Championships and/or Asian Games and the other six sprinters were members of the university's track and field team. All sprinters were involved in regular sprint training at least five times a week and resistance training two times per week. The non-sprinters were healthy university students and were physically active performing aerobic-type exercise (i.e. jogging and swimming) regularly 2 3 times a week (approximately $30 \mathrm{~min}$ each session), but none of the participants had participated in regular strength/resistance training for a minimum of 3 years prior to the start of the study. The study was conducted according to the Declaration of Helsinki and was approved by the university's Ethics Committee for Human Experiments. Written informed consent was obtained from all the participants.

Subcutaneous fat thickness was measured using ultrasound as described previously [8]. Body density was estimated from subcutaneous fat thickness using

Table 1. Body composition, thigh muscle volume and $100 \mathrm{~m}$ sprint performance in sprinters and non-sprinters.

\begin{tabular}{ccccc}
\hline & Non-Sprinter & Sprinter & $\begin{array}{c}\text { Median } \delta \\
(95 \% \text { credible interval })\end{array}$ & $\mathrm{BF}_{10}$ \\
\hline Age, years & $21.1(2.2)$ & $22.5(3.8)$ & $-0.259(-1.068,0.463)$ & 0.516 \\
Standing height, $\mathrm{m}$ & $1.58(0.05)$ & $1.63(0.05)$ & $-0.667(-1.598,0.146)$ & 1.599 \\
Body mass, $\mathrm{kg}$ & $52.0(6.4)$ & $53.5(3.7)$ & $-0.175(-0.971,0.525)$ & 0.456 \\
Body mass index, kg/m & $21.0(3.1)$ & $20.2(1.1)$ & $0.221(-0.467,1.005)$ & 0.492 \\
Body fat, \% & $22.6(4.4)$ & $12.5(0.7)$ & $3.081(1.810,4.502)$ & $15,739.5$ \\
Fat-free mass, kg & $40.2(5.2)$ & $46.8(3.3)$ & $-1.255(-2.313,-0.300)$ & 13.2 \\
Muscle volume, cm & & & & 14.3 \\
Quadriceps & $1082(237)$ & $1418(193)$ & $-1.287(-2.390,-0.315)$ & \\
Hamstrings & $381(94)$ & $648(73)$ & $-3.032(-4.482,-1.886)$ & 9487.4 \\
Adductors & $567(115)$ & $907(82)$ & $-3.22(-4.654,-1.994)$ & $23,360.2$ \\
Muscle volume relative & & & & \\
to body mass, cm ${ }^{3} / \mathrm{kg}$ & & & & \\
Quadriceps & $20.7(2.9)$ & $26.4(2.1)$ & $-2.040(-3.280,-0.957)$ & 274.7 \\
Hamstrings & $7.2(1.2)$ & $12.1(1.0)$ & $-4.350(-6.014,-3.129)$ & $1.030 \mathrm{e}+06$ \\
Adductors & $10.8(1.2)$ & $16.9(0.8)$ & $-5.312(-7.254,-4.192)$ & $4.890 \mathrm{e}+07$ \\
100m sprint time, $\mathrm{s}$ & & $12.04(0.5)$ & - & - \\
\hline
\end{tabular}

$\mathrm{BF}_{10}$ : Bayes Factor $\geq 3$ is suggestive of evidence for the alternative hypothesis whereas a Bayes factor of $\leq 0.33$ is suggestive of evidence for the null hypothesis. 
an ultrasound-derived prediction equation [9]. Percent body fat was calculated from body density using Brozek and colleague's equation [10]. Fat-free mass was estimated as total body mass minus fat mass. Body mass and standing height were measured to the nearest $0.1 \mathrm{~kg}$ and $0.1 \mathrm{~cm}$, respectively, by using an electronic weight scale and a height scale. Body mass index was calculated as body mass/standing height squared $\left(\mathrm{kg} / \mathrm{m}^{2}\right)$.

Series cross-sectional images of the thigh were obtained by magnetic resonance imaging (MRI) scans with a body coil (Signa 1.5T, GE, Milwaukee, Wisconsin, USA) as described previously [11] [12]. Briefly, the subjects lay supine in the body coil with the hip and knee being the full extension. Transverse scans were carried out every $10-\mathrm{mm}$ from the spina iliaca anterior-superior to $10-\mathrm{cm}$ below the distal end of the femur. Spin-echo, axial-plane imaging of the right-thigh was performed with 1500 -ms repetition time, $16.7-\mathrm{ms}$ effective echo time, 1 excitation, $384 \times 256$ matrix, $25-\mathrm{cm}$ field of view, $10-\mathrm{mm}$ slice thickness and 0-mm interslice gap. For each axial scan, muscle CSA computation was carried out on the quadriceps, hamstrings, and adductors (i.e. adductor longus, adductor brevis, adductor magnus, pectineus, and gracilis). From each cross-sectional image, outlines of each muscle were traced, and digitized by using a personal computer, and the muscle CSA was calculated. By summing the total CSA of the muscle along thigh length and then multiplying the sum by the interval of $10-\mathrm{mm}$, absolute muscle volume was determined. The estimated coefficient of variation of this MV measurement from test-retest $(n=5)$ was $2 \%$ [11].

A Bayesian independent samples t-test was used to determine if there were group differences in body composition and absolute and relative muscle volume of each thigh muscle with a default prior of 0.707 . A Bayes factor $\left(\mathrm{BF}_{10}\right)$ of $\geq 3$ and $\leq 0.33$ was considered evidence for the alternative and null hypotheses, respectively. For the female sprinters, we performed a correlation between sprint time and muscle volume relative to body mass using a default stretched beta prior width of 1. All Bayes factors were calculated using JASP version 0.9.0.1. Data is presented as mean (standard deviation) unless otherwise stated.

\section{Results}

There were no differences in age, height, body mass and body mass index between sprinters and controls. However, sprinters had lower percent fat and higher fat-free mass compared to non-sprinters (Table 1). Absolute muscle volumes and muscle volume relative to body mass in the quadriceps, hamstrings and adductors were greater in sprinters than in non-sprinters (Table 1). Similar results were observed in absolute and relative muscle volume in the adductor longus, the adductor brevis, the adductor magnus, pectineus, and gracilis between sprinters and non-sprinters. However, the percentage of each individual muscle to the adductor muscle volume appeared similar between the two groups (Table 2).

In sprinters, percent body fat did not correlate with $100 \mathrm{~m}$ sprint time. There was no evidence for a correlation between sprint time and quadriceps muscle 
Table 2. Absolute and relative muscle volume of individual adductor muscles.

\begin{tabular}{|c|c|c|c|c|}
\hline & Non-Sprinter & Sprinter & $\begin{array}{c}\text { Median } \delta \\
\text { (95\% credible interval) }\end{array}$ & $\mathrm{BF}_{10}$ \\
\hline \multicolumn{5}{|l|}{ Muscle volume $\left(\mathrm{cm}^{3}\right)$} \\
\hline Adductor longus & $88(25)$ & $144(24)$ & $-2.057(-3.241,-0.590)$ & 297.9 \\
\hline Adductor brevis & $69(16)$ & $113(21)$ & $-2.041(-3.271,-0.873)$ & 274.5 \\
\hline Adductor magnus & $332(59)$ & $524(52)$ & $-3.223,(-4.687,-2.00)$ & $25,056.4$ \\
\hline Pectineus & $28(6.7)$ & $39(7)$ & $-1.292(-2.390,-0.337)$ & 14.8 \\
\hline Gracilis & $51(23)$ & $87(11)$ & $-1.775(-2.923,-0.712)$ & 91.2 \\
\hline \multicolumn{5}{|c|}{ Muscle volume relative to body mass, $\mathrm{cm}^{3} / \mathrm{kg}$} \\
\hline Adductor longus & $1.67(0.34)$ & $2.68(0.34)$ & $-2.744(-4.063,-1.540)$ & 4147.9 \\
\hline Adductor brevis & $1.31(0.22)$ & $2.10(0.31)$ & $-2.604(-3.925,-1.053)$ & 2526.5 \\
\hline Adductor magnus & $6.37(0.72)$ & $9.81(0.84)$ & $-4.066(-5.797,-2.710)$ & $466,876.1$ \\
\hline Pectineus & $0.54(0.10)$ & $0.73(0.12)$ & $-1.411(-2.485,-0.421)$ & 23.4 \\
\hline Gracilis & $0.95(0.31)$ & $1.62(0.17)$ & $-2.484(-3.893,-1.396)$ & 1442.0 \\
\hline \multicolumn{5}{|c|}{ Percentage of total adductors muscle volume, $\%$} \\
\hline Adductor longus & $15.3(2.4)$ & $15.9(2.2)$ & $-0.144(-0.920,0.567)$ & 0.439 \\
\hline Adductor brevis & $12.1(1.3)$ & $12.4(1.7)$ & $-0.108(-0.870,0.604)$ & 0.420 \\
\hline Adductor magnus & $58.9(4.0)$ & $57.9(3.4)$ & $0.174(-0.523,0.963)$ & 0.453 \\
\hline Pectineus & $4.9(0.9)$ & $4.3(0.7)$ & $0.566(-0.200,1.494)$ & 1.167 \\
\hline Gracilis & $8.7(2.3)$ & $9.5(0.9)$ & $-0.333(-1.161,0.365)$ & 0.614 \\
\hline
\end{tabular}

$\mathrm{BF}_{10}$ : Bayes Factor $\geq 3$ is suggestive of evidence for the alternative hypothesis whereas a Bayes factor of $\leq 0.33$ is suggestive of evidence for the null hypothesis.

volume relative to body mass $\left[\mathrm{r}=-0.186, \mathrm{BF}_{10}: 0.423\right.$, median $\delta$ (95\% credible interval) $-0.145(-0.640,0.409)]$, hamstring muscle volume relative to body mass $\left[\mathrm{r}=-0.416, \mathrm{BF}_{10}: 0.765\right.$, median $\delta(95 \%$ credible interval $)-0.332(-0.760$, $0.223)]$, or adductor muscle volume relative to body mass $\left[\mathrm{r}=-0.447, \mathrm{BF}_{10}\right.$ : 0.866 , median $\delta$ (95\% credible interval) $-0.358(-0.775,0.194)]$. Within the adductors, there was no evidence for a correlation between sprint time and adductor longus muscle volume relative to body mass $\left[\mathrm{r}=0.162, \mathrm{BF}_{10}: 0.409\right.$, median $\delta$ (95\% credible interval) $0.126(-0.426,0.627)]$ or adductor magnus muscle volume relative to body mass $\left[\mathrm{r}=-0.259, \mathrm{BF}_{10}: 0.482\right.$, median $\delta(95 \%$ credible interval) $-0.203(-0.680,0.355)]$. However, there was evidence for a correlation between sprint time and adductor brevis muscle volume relative to body mass [ $\mathrm{r}$ $=-0.652, \mathrm{BF}_{10}$ : 3.028, median $\delta(95 \%$ credible interval $\left.)-0.548(-0.870,0.040)\right]$.

\section{Discussion}

The main findings of the current study were that 1 ) adductors muscle volume was approximately $60 \%$ greater in female $100 \mathrm{~m}$ sprinters compared to age- and height-matched non-sprinters; 2) the percentage of each individual adductor 
muscle relative to the total adductor muscle volume appeared similar between the two groups; and 3) there was a significant correlation between adductor brevis muscle volume relative to body mass and $100 \mathrm{~m}$ sprint time in female sprinters. Of note, the total adductor muscle volume as well as other individual muscles within the adductors did not correlate with sprint performance.

There are few studies investigating the individual muscles making up the total thigh volume as measured by MRI in athletes. In the present study, total adductor muscle volume of female sprinters was $907 \mathrm{~cm}^{3}$ on average. This absolute muscle volume of the adductors was similar as the value of physically active young students $\left(913 \mathrm{~cm}^{3}\right)$ reported by Ogawa et al. [13] Recently, Sugisaki et al. [4] reported MRI-measured muscle volume of the adductor splus gracilisin male $100 \mathrm{~m}$ sprinters $\left(1278 \mathrm{~cm}^{3}\right)$. The difference in adductors muscle volume between male and female sprinters was approximately $370 \mathrm{~cm}^{3}$, while the difference in the quadriceps muscle volume was approximately $800 \mathrm{~cm}^{3}\left(2210 \mathrm{~cm}^{3}\right.$ in male sprinters and $1418 \mathrm{~cm}^{3}$ in female sprinters). Calculated percentage of adductors relative to total thigh muscle volume was relatively higher in our female sprinters (31\%) compared to male sprinters (28\%). However, the percentage value of our female non-sprinters was $28 \%$. The significance of this potential sex difference is not known and future research is needed to better understand how the adductors might change with sprint training.

In the present study, we found that adductor brevis muscle volume relative to body mass was correlated with $100 \mathrm{~m}$ sprint time. Our data suggests that we are $95 \%$ confident that the true effect lies between an $r$ value of -0.87 and an $r$ value of 0.040. Although the credible interval was wide, this particular muscle may suggest a target of investigation in future studies. This is the first study to investigate the correlation between the muscle volume of each individual muscle within the adductors and sprint performance in sprinters. Previous studies reported that there were no correlations between total adductors muscle volume or adductor muscle CSA relative to body mass and sprint performance [3] [4]. In line with the previous studies, our results also indicated no correlation between total adductor muscle volume and $100 \mathrm{~m}$ sprint time in female sprinters. Previously reported electromyographic studies [6] [7] measured muscle activity (fine wire electrodes system) of the lower body muscles. Although the adductor longus and adductor magnus were examined during sprint running, the adductor brevis was not measured. This may be related, in part, to the difficulty of measuring muscle activity in this muscle (location is inguinal area and relatively deep). The adductor brevis muscle acts to adduct the thigh at the hip joint and flex and medially rotate the thigh [5]. This muscle also contributes to flexion of the thigh when the foot leaves the ground and begins to swing forward during running [14]. It is known that the psoas major muscle is a muscle for the hip flexion and that muscle volume/CSA of the psoas major is associated with sprint performance [1] [2] [4]. The adductor brevis may support the flexion and medially rotation of the thigh together with the psoas major, which may contribute to sprint running performance in female $100 \mathrm{~m}$ sprinters. 


\section{Conclusion}

In conclusion, we found a correlation between adductor brevis muscle volume relative to body mass and $100 \mathrm{~m}$ season best time, although there was no correlation between total adductors muscle volume and sprint performance. These results suggest that the adductor brevis may play a role in superior sprint performance in female sprinters.

\section{Acknowledgements}

The authors would like to thank the individuals who voluntarily gave their time to participate in this study. This research did not receive any specific grant from funding agencies in the public, commercial, or not-for-profit sectors.

\section{Conflicts of Interest}

The authors declare that they have no conflicts of interest relevant to the content of this study.

\section{References}

[1] Copaver, K., Hertogh, C. and Hue, O. (2012) The Effects of Psoas Major and Lumbar Lordosis on Hip Flexion and Sprint Performance. Research Quarterly for Exercise and Sport, 83, 160-167. https://doi.org/10.1080/02701367.2012.10599846

[2] Hoshikawa, Y., Muramatsu, M., Iida, T., Uchiyama, A., Nakajima, Y., Kanehisa, H. and Fukunaga, T. (2006) Influence of the Psoas Major and Thigh Muscularity on 100-m Time in Junior Sprinters. Medicine and Science in Sports and Exercise, 38, 2138-2143. https://doi.org/10.1249/01.mss.0000233804.48691.45

[3] Sugisaki, N., Kanehisa, H., Tauchi, K., Okazaki, S., Iso, S. and Okada, J. (2011) The Relationship between 30-m Sprint Running Time and Muscle Cross-Sectional Areas of the Psoas Major and Lower Limb Muscles in Male College Short and Middle Distance Runners. International Journal of Sports and Health Science, 9, 1-7. https://doi.org/10.5432/ijshs.20100018

[4] Sugisaki, N., Kobayashi, K., Tauchi, K. and Kanehisa, H. (2018) Associations between Individual Lower Limb Muscle Volume and 100-m Sprint Time in Male Sprinters. International Journal of Sports Physiology and Performance, 13, 214-219. https://doi.org/10.1123/ijspp.2016-0703

[5] Pansky, B. (1996) Review of Gross Anatomy. 6th Edition, McGraw-Hill, New York.

[6] Mann, R.A., Moran, G.T. and Dougherty, S.E. (1986) Comparative Electromyography of the Lower Extremity in Jogging, Running, and Sprinting. American Journal of Sports Medicine, 14, 501-510. https://doi.org/10.1177/036354658601400614

[7] Montgomery, W.H., Pink, M. and Perry, J. (1994) Electromyographic Analysis of Hip and Knee Musculature during Running. American Journal of Sports Medicine, 22, 272-278. https://doi.org/10.1177/036354659402200220

[8] Abe, T., Dankel, S.J., Buckner, S.L., Jessee, M.B., Mattocks, K.T., Mouser, J.G., Bell, Z.W. and Loenneke, J.P. (2019) Differences in 100-m Sprint Performance and Skeletal Muscle Mass between Elite Male and Female Sprinters. Journal of Sports Medicine and Physical Fitness, 59, 304-309. https://doi.org/10.23736/S0022-4707.18.08267-1

[9] Abe, T., Kondo, M., Kawakami, Y. and Fukunaga, T. (1994) Prediction Equations 
for Body Composition of Japanese Adults by B-Mode Ultrasound. American Journal of Human Biology, 6, 161-170. https://doi.org/10.1002/ajhb.1310060204

[10] Brozek, J., Grande, F., Anderson, J.T. and Keys, A. (1963) Densitometric Analysis of Body Composition: Revision of Some Quantitative Assumption. Annals of the New York Academy of Sciences, 110, 113-140. https://doi.org/10.1111/j.1749-6632.1963.tb17079.x

[11] Abe, T., Kearns, C.F. and Fukunaga, T. (2003) Sex Differences in Whole Body Skeletal Muscle Mass Measured by Magnetic Resonance Imaging and Its Distribution in Young Japanese Adults. British Journal of Sports Medicine, 37, 436-440. https://doi.org/10.1136/bjsm.37.5.436

[12] Abe, T., Dankel, S.J., Buckner, S.L., Jessee, M.B., Mattocks, K.T., Mouser, J.G., Bell, Z.W. and Loenneke, J.P. (2019) Magnetic Resonance Imaging-Measured Skeletal Muscle Mass to Fat-Free Mass Ratio Increases with Increasing Levels of Fat-Free Mass. Journal of Sports Medicine and Physical Fitness, 59, 619-623. https://doi.org/10.23736/S0022-4707.18.08683-8

[13] Ogawa, M., Yasuda, T. and Abe, T. (2012) Component Characteristics of Thigh Muscle Volume in Young and Older Healthy Men. Clinical Physiology and Functional Imaging, 32, 89-93. https://doi.org/10.1111/j.1475-097X.2011.01057.x

[14] Wirhed, R. (2006) Athletic Ability and the Anatomy of Motion. 3rd Edition, Elsevier Health Sciences, Amsterdam, Netherlands. 